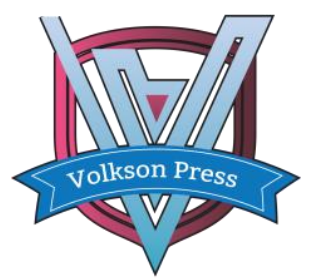

Contents List available at VOLKSON PRESS

Economics \& Management Innovations(EMI)

DOI : http://doi.org/10.26480/icemi.01.2017.309.312

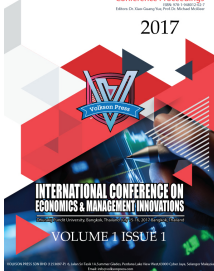

\title{
Distortions in perception of warning signals about risks and threats to an organization
}

\author{
Bogdan Ćwik ${ }^{1}$ \\ ${ }^{1}$ Wojskowa Akademia Techniczna w Warszawie, ul. Gen. Sylwestra Kaliskiego 2, 00-908 Warszawa, Poland \\ email:bogdan.cwik@wat.edu.pl
}

This is an open access article distributed under the Creative Commons Attribution License, which permits unrestricted use, distribution, and reproduction in any medium, provided the original work is properly cited.

\section{ARTICLE DETAILS}

\section{Article History:}

Received 02 october 2017 Accepted 06 october 2017

Available online 11 october 2017

\section{Keywords:}

signal perception, warning signal, distortion in perception, monitoring of risks and threatens, perception in conditions of anxiety, perception in conditions of

\section{ABSTRACT}

The main problem of this paper concerns significant distortions in warning signals perception and associated limited effectiveness of warning systems in most monitoring systems and early warning systems of today's organizations. Particularly important are those distortions that result from various emotional states of a person responsible for perceiving warning signals. Making people responsible for monitoring the risk aware of existing different channels for providing warning information depending on the emotional state of the perceivers, seems to be the solution to this issue. This awareness should enable to significantly improve the perception of risk through simple information activity. The innovation of conducted research and analysis are three models that together represent the basic mechanisms of warning signals perception. Relatively new proposal submitted mainly by researchers of psychological sciences, regarding the fragmentary work on this issue, is to include jointly those three presented models in monitoring systems of risks and threats to an organization. The usefulness of taking into account those proposed models was presented in the course of two empirical studies described in this paper.

\section{Introduction}

Many today's organizations are forced to perform their tasks in the presence of various threats. These dangers are evident at every step and are present in different dimensions. The effective perception of warning signals is a problem of many organizations where, on the one hand, important warning signals are omitted or ignored, and, on the other hand, unnecessary mobilization of resources and related costs take place as a result of "false alarm". The above facts leads to a deeper reflection on the perception of threats.

The aim of this study is to point two different warning perception channels in the perceivers' minds which are triggered in different states of emotional tension. It can be particularly seen during sudden, unexpected situations when person perceiving threats is subjected to intense mental stress like: communication catastrophes, terror attacks, strong financial market failures, natural disasters. The effects of inadequate perception of the real situation by different channels of perceiving information about risk and threatens are usually: cascade of series of irrational reflex actions such as sudden withdrawal of invested financial market funds, panic attacks in a mass event and during a communication catastrophe results in permanent neurological disease.

At first glance, it seems that perception issues, including perception of threats, are thoroughly investigated and developed. However, it seems to be an innovation to propose an approach to this problem from the point of view of scientific discipline which is a discipline of management science.

\section{Research on the perception of threats in the conditions of strong} emotional tension

To confirm and deepen the phenomena as well as to confirm the theoretical models the two following separate researches have been carried out: secondary research based on the results of the research conducted by prof. Frank Lasogga of the University of Dortmund on the socalled prehospital (initial) care during the communication catastrophe and my own research on the perception of situation during sudden falls in the financial markets.

The first study concerned traffic accidents, especially accidents with a high number of injured. Then emergency services in Germany have voluntary service teams providing prehospital care. Those teams get to the place of accident even before the emergency services arrive and make first contact with the victims giving basic information about the current situation, asking about well-being, declaring their willingness to help. Taking advantage of those teams and using the method of uncategorized interview, the scientists conducted research among service team members and accidents victims to whom those prehospital care were and were not given. The study included 200 interviews [1]

The study found that the victims are in a very difficult situation, not only because of their injuries, but also because of the measures and information about the current situation provided by the rescue teams taking part in the action. For instance, the victims admitted that during the rescue action they heard the following: "see how this one looks like", "he is no longer worth taking care of", "let's leave him, he is nothing" - this information were often taken personally by the victims. Mental stress in such situations is so great that combined with physical suffering lead, among others, to mental disturbance in the organism. But at the same time, it turns out that if in the place of an accident there is a person saying, there have been an accident, you are seriously injured, but you will be given medical help soon, or asking what he/she can do to help, or declaring to go to the apartment and take the left dog to a friend, the tension is immediately reduced and the percentage of mental complications resulting in this event to these people is significantly smaller.

A summary of accident victims shows that more than $90 \%$ of those who were not given the prehospital care, suffer negative physical and psychological consequences while only about $75 \%$ of victims who receive the initial medical care, admit feeling negative physical and psychological consequences of the accident. The subject requires deep analyzes, but there is a considerably significant difference, as indicated by the following fraction test for large samples, which tested the null hypothesis of no statistical significance of presented percentages, i.e. that prehospital care does not result in negative mental and physical consequences for accident victims. The sample consisted of 59 people.

The statistics for this test are as follows:

$z=\frac{\hat{p}-p_{o}}{\sqrt{p_{o} q_{o} / n}}=\frac{0,9-0,75}{\sqrt{(0.750 .15) / 59}}=2.66$ 
where:

$\hat{p}=0.90 \quad \mathrm{n}=59$ (Number of respondents)

$p_{o}=0.75 \quad q_{o}=1-p_{o}=0.25$

$z_{k r}=1.96$

As we can see $\mathrm{z}>1.96$ which means that the null hypothesis should be rejected and provision of prehospital care positively affects mental and physical consequences of accident victims.

The second study was conducted in another field and related to the perception of risk signals by individual investors in the financial markets. This study was carried out using the tense situation on the financial markets in Poland in 2008-2009 and the survey was conducted among individual investors who invested their own funds on the stock exchange or in investment funds. In the course of research, it appears that "investor rooms" at brokerage offices are an excellent laboratory providing information on behavior and attitudes towards risk and threats. The study was conducted in the investor rooms of four brokerage houses in Warsaw using the methods of participant observation and non-categorized (unstructured) interview. The investigated were not informed about the conducted observations and the leading researcher had previously invested EUR 20000 in the financial market and played the role of one of the investors who consulte with others on what decisions to make on a given day, why it was better to do so, and not otherwise, listen explanations, comments, conclusions as well as friendly recommendations. 10-21 people were observed anonymously on a given day. The total number of made observations is 267. Similar interviews in the form of friendly conversations were conducted on how to recognize the signals that the situation on financial markets is going to change, how to make a choice whether to enter the market with financial resources or whether to withdraw temporarily as well as on how long to stay on the market. 37 interviews were conducted during the study.

The study was conducted between October 2008 and May 2009. During this period the situation on the financial markets in Poland changed many times. By participating directly in the subsequent phases of spreading crisis, reading analysts' analysis of the financial markets, listening to comments and recommendations from brokerage houses, financial advisors in banks, listening to media reports, reading reviews and comments on websites and taking part in direct conversations with investors the author participated directly in the various phases of moods on the financial markets: from extreme euphoria, through intermediate phases, to extreme depression.

Several different behaviors and attitudes have emerged in the course of the study with signals emerging from various sources about development in the financial markets. The interviewed were subjected to intense emotional stress because they had to perceive signals and make decisions under conditions of possible loss of invested funds, which for some of them were all savings.

In general, there were observed two types of behaviors during strong falls on the financial markets:

- $\quad$ Panic, screams, uncontrollable words and behavior, involuntary decisions, mass withdrawal from the financial markets, ignoring expert hints, reminding the chaotic run of crowd during an escape from a dangerous spot.

- Nervousness, but attempts to make rational decisions, estimations and forecasting for the next days, consultations with experts.

The results of both studies indicate that there are two different types of risk perception in conditions of high emotional stress. The first one is the situation where the information was processed under conditions of high stress but rationally and the other where the information was processed in stress and unreasonably.

At least a partial explanation of the reasons for the differences in perception should be provided by the following models: warning signal model, integrated model of warning signal perception, model of transmitting warning information in different emotional states.

\section{Warning signal model}

The basic assumption of this model is that the perception of a warning signal is actually the perception of the sign. The sign can be considered according to Charles S. Peirce's Theory of Signs [2] and its development presented by Elina Hiltunen [3] in the form of three-dimensional model of visibility of the future sign (Fig. 1). The dashed line shown in Fig. 1 can be interpreted as the trajectory of the visibility of a sign containing a warning signal.

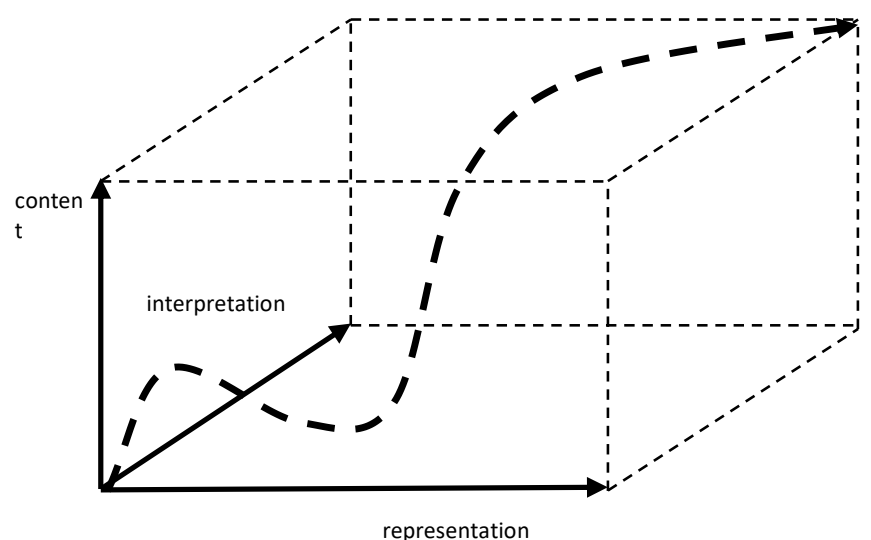

Figure 1. Three-dimensional model of a sign containing the warning signal

Source: author's own elaboration.

The model presented in Fig. 1 illustrates the triadic concept of a warning sign, in which three components are distinguished: the interpretation, the representation and the content of the sign, where the content of the sign is the size of a negative impact that poses a threat to the organization. A specific level of visibility can be assigned to each of these components. In the process of perception the observer directly reads the representation of the signs, where the dashes read on the thermometer are a representation and the temperature is the correlated content (reaction). However, it still requires interpretation, since, e.g. a read value of 40 Celsius degrees may present a significant risk if relates to human body temperature or ambient temperature, but in a cooling system of an internal combustion engine or in a home heating system, it proves the proper operation of the devices. At the same time, each of the components of such a sign can be expressed in a specific measuring scale, in which we can point the initial value, for example zero or insignificant value, the intermediate values and the final value (very significant).

\section{Integrated model of warning signal perception}

Taking into account the above model, the following model of warning signal perception is proposed (Fig. 2). The presented model is integrated by cognitive processes, which include attention, memory and thinking. In Fig. 2 we can see two contrary directed streams of processes, i.e. bottomup processes from outer environment and top-down processes from the mind.

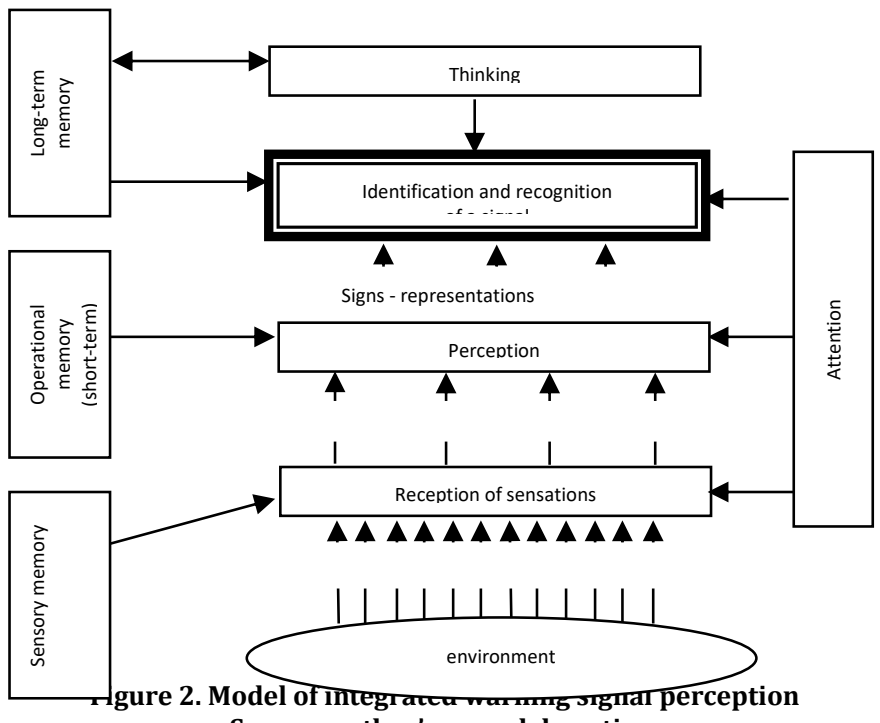

Source: author's own elaboration.

The process of integrated perception of the sign presented in Fig. 2 starts with sensory recording, which translates the recorded light or sound waves into the nerve impulses in the senses, resulting in sensations, i.e, reflections of elementary sensory qualities recorded as a result of sensory data reception. Sensory data means stimuli, where stimulus is understood 
as an environmental factor containing energy and triggering a specific reaction of the body. These stimuli are processed into impressions (sensations) which take the form of graphic symbols or images and are recorded (received, read) as sign representations. There appear so-called sign insights which are performed in bottom-up processes. Warning signals related to threats are generally received in visual structures and channels or ear structures and channels of the perceiver - biological details of this process are the material for separate specialist studies, such as the work of Peter H. Lindsay and Donald A. Norman [4]

The recorded observations are confronted with parallel processes of selection and categorization, which are realized using memory and thinking in top-down processes, resulting in recognition and identification of the sign content. Such perception is a process of active reception, analysis and interpretation of sensory phenomena. In this process, the incoming sensory information is processed in such a way to adjust it to one's knowledge about the surrounding world [5], [6].

In general, the identification and recognition of any object, phenomenon or event is nothing more but the interpretation of the perceived sign representations, including:

1) Assigning the meaning to observations,

2) Conscious observation of subject matter:

- giving the perceived representation a name or defining what it is;

- $\quad$ issuing quantitative assessments of the sign content, i.e. how much is it;

- $\quad$ issuing quality assessments of the sign content, i.e. how is it;

- $\quad$ issuing pragmatic judgments, e.g. determination the purpose and impact of the object.

In the case of warning signals, it will mean recognition of a specific reaction, reading its size, comparing it with limit values, risk assessment when exceeding limits taking into account the level of the stress in the environment, decision about sending a warning message to the management.

The processes of perceiving warning signals realized according to presented model in conditions of high stress are distorted by emotional factors when in certain situations, top-down processes are implemented partially or their implementation is omitted.

\section{Model of transmitting warning information in different emotional states}

Emotions, mainly fear and anxiety, are the cause of different stress perceptions. One of the basic works in this field was presented by Michael Lewis and Jeannette M. Haviland-Jones who wrote: "Defensive responses formed in the process of evolution are only beneficial if they are triggered appropriately The condition for their proper functioning is the existence of a perceptual system that will enable accurate localization of the threat. [...]. Effective defense must be activated quickly. Early detection of the threat is therefore very desirable. In addition, the threatening stimulus must be detected always whenever it is in field of the perception, regardless of the current matter of attention. Together with the tendency for false positive reactions, this means that hazard identification should be based on a rapid shallow analysis of potential danger rather than on the laborious, detailed and complete decoding of the stimulus meaning. From a functional evolutionary perspective, it is clear that the responsibility for detecting a threat (risk or hazard) should rest with early perceptual parallel processing mechanisms that determine the danger based on the relatively simple features of the stimulus" [7].

My own studies and analyzes indicate that the basic element of emotion management in the body is the amygdala (Fig. 3). Michael Lewis and Jeannette M. Haviland-Jones write about it as follows: The emotional PC of the brain is an amygdala. In its structures there is performed an assessment of the stimuli importance. It allows the amygdala to capture the threatening stimuli even before the time-consuming stimuli analyze in the cerebral cortex. This mechanism has had an evolutionary advantage, but today it may contribute to unfavorable behavior" [8]. The aforementioned amygdala is a key element of a rapid threat information channel. The neuronal structure of such a system has been presented, among others, by Joseph E. LeDoux. [9]. As a result of the research and analysis conducted by this author, it turned out that living organisms developed "the way to fast and irreproachable transfer of information". This is a monosynaptic connection that allows the amygdala to provide instant information about the basic features of the stimulus, bypassing the traditional information pathway that is the thalamocortical area. Thanks to this, the amygdala may initiate an early activation of defensive reactions. Joseph E. LeDoux states that the adaptive feature of this system is also the tendency for false positive reactions. With reference to the evolution, it is advantageous because it is better to survive an unnecessarily initiated defensive reaction than not to initiate it when the threat is real. Fig. 3 shows rapid transfer of information in the event of a serious threat.

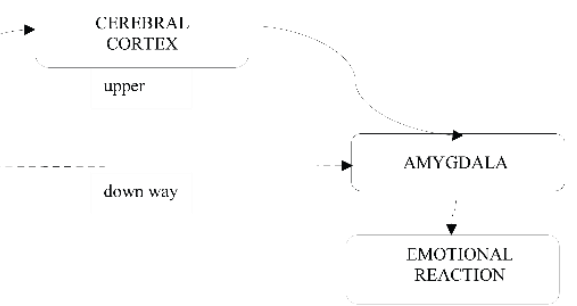

Figure 3. Up and down way to amygdala

Source: author's own elaboration.

The warning signal becomes a stimulus when triggered by the sudden and strong threat. Information about this stimulus reaches amygdala through thalamus which is a relay station (Figure 3) - directly (down way) or indirectly through the cerebral cortex (upper way). The direct way is shorter and therefore the transfer of information is faster than when it passes indirectly through the cerebral cortex. As the lower way bypasses the cerebral cortex, it is impossible to use its operation, including launching in-depth processes of perception. As a result, the down way provides the amygdala with an image of the stimulus that is not fully processed. Thus, this is a fast way to quickly react to a potential threat, without thorough analysis of what the stimulus actually represents Simply the down way is responsible for emotional reactions which the organism does not understand. Such a system may cause relevant cognitive disturbances and trigger: reflexive decisions, reflexive choices, reflexive assessments, different from those that would have been done when using cerebral cortex. In extreme cases there appears a mutually reinforced collective assessment of the situation that is very dangerous as in the case of further reinforcements, they may form the cascade and result in panic.

The emotion that causes warning signals processing through the lower path is anxiety. Michael Lewis and Jeannette M. Haviland-Jones distinguished fear and anxiety in the following way: "The term anxiety means fearful anticipation of future threats or misfortunes accompanied by dysfunctional feelings or somatic symptoms of stress. Fear differs from anxiety as it is triggered by a recognizable stimulus. [...]. Thus, the difference between those two terms is related to the fact that anxiety is often pre-stimulant (i.e. anticipatory versus more or less real threat), but fear is consequential (secondary, i.e. triggered by a particular stimulus) [...]. Fear is related to behavioral remedies, especially escape and avoidance. When the attempts to cope fail (e.g. the situation cannot be controlled), fear becomes anxiety" [10].

As can be seen from the above, anxiety may be defined as unsolved fear or state of untargeted stimulation following threat perception. It is the anxiety-related emotions that trigger a fast path of transferring information. Above facts also show that in the state of anxiety, the cerebral cortex does not process information. Thus, in the process of perception of sudden and strong threats, higher mental operations are not performed. In the state of anxiety, the perception of warning signals is carried out by the amygdala and associated older structures of the brain (limbic system). While fear is associated with rationality, it means conscious processing of information about a given threat. In the atmosphere of fear the information is processed using cerebral cortex. As a result, in the conditions of fear, standard processes of thinking are carried out including processes of reasoning, as well as processes of imagination. This involves the availability of specific data in the memory resources which are the base for categorization. As a result, full processes of threat identification and recognition are realized based on received signals.

\section{Conclusions}

The differences in threat perception shown in the research may be justified by distortions in the perception of warning signals. Partial identification of the mechanisms of these distortions is possible thanks to presented models of: warning signal, integrated warning signal perception and transmitting warning information in different emotional states. 
In conditions of strong psychic tension, the mind of the perceiver processes the warning signals of a triadic structure. Normally, the perception of these signals follows the integrated perception of the warning signal (Fig. 2). However, depending on the emotional state of the perceiver, these signals are processed either by a rational (normal) or a fast way of transmitting information. Standard way of transmitting information goes through the cerebral cortex where rational interpretation of the read signals takes place in the processes of thinking, imagining and others. However, fast information flow bypasses the cerebral cortex and launches simple biological scenarios for security solutions in the organization. A situation where the fast information flow has been launched may lead to significant distortions in the effective perception of threats. However, the awareness of presented mechanisms by the person responsible for monitoring risks and threats may enable to change the way of transmitting information in the perceivers' minds using simple information interactions. This is confirmed by the studies on traffic accidents victim as well as by my own research conducted on investors in the financial markets.

\section{References}

[1] F. Lasogga, G. Gasch, Psychische Erste Hife bei Unfällen, Edewecht (2013).

[2] P. Janik, Koncepcja przekonania w ujęciu semiotycznopragmatycznym: Charles S. Peirce, Wydawnictwo WAM, Cracow (2011), p. 81-115.

[3] E. Hiltunen, Foresight and innovation: how companies are coping with the future, Palgrave Macmillan, New York, NY (2013).

[4] P. H. Lindsay, D. A. Procesy przetwarzania informacji u człowieka, wprowadzenie do psychologii, PWN, Warszawa (1991).

[5] P. G. Zimbardo, Psychologia i życie, Wydawnictwo Naukowe PWN, Warszawa, (2012), p. 264-307.

[6] J. S. Bruner, Beyond the information given: studies in the psychology of knowing, Taylor \& Francis Group, (2010), p. 32-226.

[7] M. Lewis and J. M. Haviland-Jones, Handbook of emotions, The Guilford Press, (2008), p. 725.

[8] M. Lewis and J. M. Haviland-Jones,, Handbook of emotions, The Guilford Press, (2008), p. 210-229.

[9] J. E. LeDoux, The emotional brain revisited, Copernicus Center Press, Kraków (2014).

[10] M. Lewis and J. M. Haviland-Jones, Handbook of emotions, The Guilford Press, (2008), p. 720-721. 